\title{
A Small Planar Antenna for 4G Mobile Phone Application
}

\author{
Hu Jian-rong, Li Jiu-sheng, and Wu Di \\ Centre for THz Research, China Jiliang University, Hangzhou 310018, China \\ Correspondence should be addressed to Li Jiu-sheng; forever-li@126.com \\ Received 5 November 2015; Revised 26 February 2016; Accepted 2 March 2016 \\ Academic Editor: Renato Cicchetti
}

Copyright (C) $2016 \mathrm{Hu}$ Jian-rong et al. This is an open access article distributed under the Creative Commons Attribution License, which permits unrestricted use, distribution, and reproduction in any medium, provided the original work is properly cited.

\begin{abstract}
The analysis and design of a small planar multiband antenna operating in the $4 \mathrm{G}$ frequency bands are presented. The numerical and experimental results demonstrated that the proposed antenna satisfies the requirement of $6 \mathrm{~dB}$ return loss for the impedance bandwidth of the LTE700/LTE2300/LTE2500 and WiMAX3500 bands. The gains at $750 \mathrm{MHz} / 2.3 \mathrm{GHz} / 2.6 \mathrm{GHz} / 3.5 \mathrm{GHz}$ are $2.1 \mathrm{dBi} / 4.9 \mathrm{dBi} / 4.7 \mathrm{dBi} / 4.3 \mathrm{dBi}$, respectively. The measured radiation patterns verify the suitability of the antenna to be employed in mobile phones. The dimensions of the radiant patch are $49 \times 10 \mathrm{~mm}^{2}$. The proposed antenna can be easily fabricated and customized to various $4 \mathrm{G}$ mobile phones as a compact internal antenna.
\end{abstract}

\section{Introduction}

With the rapid development of the fourth-generation $(4 \mathrm{G})$ mobile communication technologies, the mobile phone antennas have received substantial attention because of the wide applications made available in such systems [1-4]. In fact, these antennas, which are an important part of mobile phone terminals, affect the overall performance of these communication systems. The usual mobile phone antennas have been proved unable to meet the $4 \mathrm{G}$ wireless communication requirements of the multiband and broadband applications [5-7]. In the last few years, a variety of small Long Term Evolution (LTE) mobile phone antennas have become the hot topic of the communication industry research [8-11]. To address the difficulties of integrating antennas in $4 \mathrm{G}$ mobile phones, many efforts have been made to expand the performance of the antennas in the LTE bands [12-16]. However, these design solutions generally require large size or volumes, which may be not compatible with the new generation of mobile phone applications. Because of the extremely limited volume of a mobile terminal, it is very important to synthesize compact multifunctional and broadband antennas. In the near future, these consumer electronic devices will be capable of integrating multibands protocols (LTE, WiMAX, etc.) into one single communication system. Thus, the antenna for $4 \mathrm{G}$ mobile phones must be compact size and low profile.
In this paper, a multiband antenna for a $4 \mathrm{G}$ mobile terminal application is proposed. The antenna is made by means of compact multiresonator planar elements that occupy a size of $49 \times 10 \times 1.6 \mathrm{~mm}^{3}$. It covers multibands which include the LTE700 (698-787 MHz), LTE2300 (2305$2400 \mathrm{MHz})$, LTE2500 (2500-2690 MHz), and WiMAX3500 $(3390-3600 \mathrm{MHz})$ operations. Good radiation characteristics within the operative antenna frequency band are obtained. Details of the proposed antenna design and of the related parametric analysis are presented and discussed in the next sections. With the attractive features described above, the proposed antenna is a promising candidate for wireless devices.

\section{Antenna Configuration}

The geometry of the proposed LTE-printed antenna is depicted in Figure 1. The antenna has a planar structure and a simple configuration consisting of two horizontal- $\mathrm{U}$ rings, a feed, a shorting line, and a ground plane. It is fed by a $50 \Omega$ minicoaxial line connected between the feeding point (point A) of the driven monopole and the phone-display ground point (point $\mathrm{B}$ ). The proposed antenna is fabricated on a commercially available FR4 substrate having thickness of $1.6 \mathrm{~mm}$, relative permittivity of 4.4 , and loss tangent of 0.024 . 


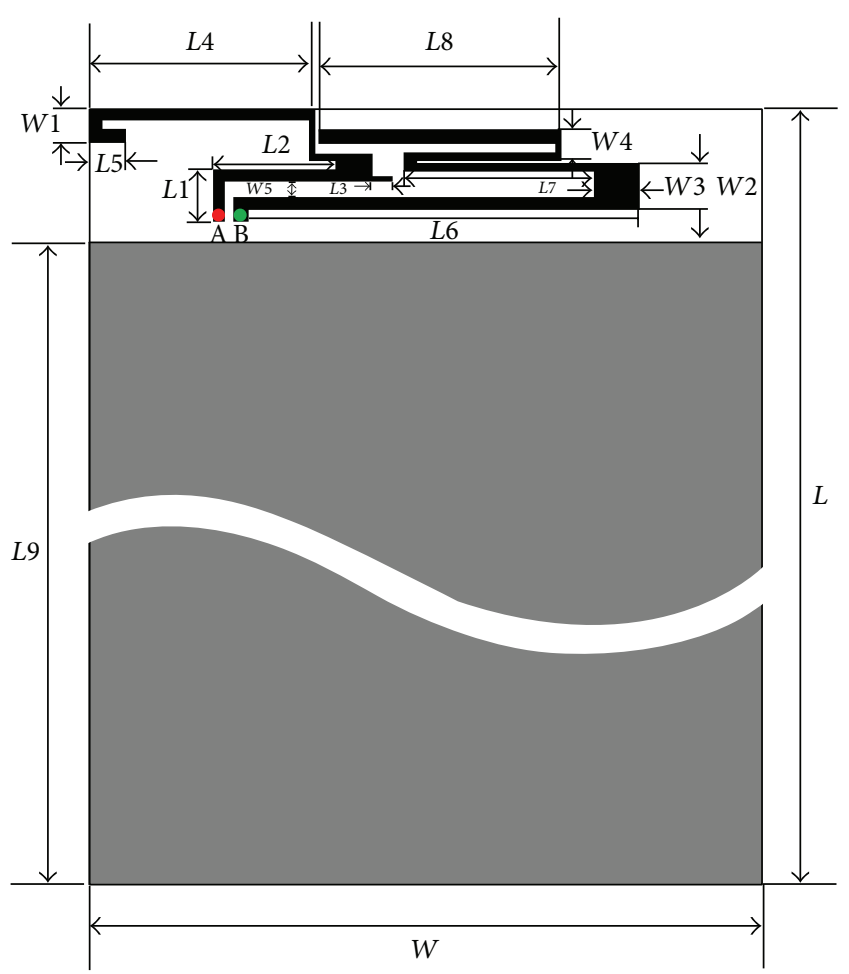

FIGURE 1: Geometries of the proposed antenna.

The system ground plane of the antenna has dimensions of $108 \times 60 \mathrm{~mm}^{2}$. The area where the ground plane is not present has dimensions of about of $49 \times 10 \mathrm{~mm}^{2}$. Thus, the size of this antenna is suitable for mobile phone applications.

The values of the design parameters shown in Figure 1 were evaluated by means of an extensive parametric analysis performed using the commercial software HFSS. After completing the optimization process the dimensions of the proposed antenna have been set as follows: $L=120 \mathrm{~mm}$, $L 1=4.5 \mathrm{~mm}, L 2=11 \mathrm{~mm}, L 3=2 \mathrm{~mm}, L 4=20 \mathrm{~mm}$, $L 5=3 \mathrm{~mm}, L 6=34 \mathrm{~mm}, L 7=16 \mathrm{~mm}, L 8=20 \mathrm{~mm}$, $L 9=108 \mathrm{~mm}, W=60 \mathrm{~mm}, W 1=3 \mathrm{~mm}, W 2=4 \mathrm{~mm}$, $W 3=4 \mathrm{~mm}, W 4=2.5 \mathrm{~mm}$, and $W 5=1.5 \mathrm{~mm}$. Based on the optimized design dimensions, a prototype of the proposed antenna depicted in Figure 2 was realized and tested.

\section{Parameters Study}

Figure 3 shows the frequency behavior of the antenna reflection coefficient for different lengths of the geometrical parameter $L 2$ when the other parameters are kept constant to their optimized values. From Figure 3 it appears that the length $L 2$ mainly controls the second antenna resonance frequency $f_{2}$. In particular, it is found that as the length $L 2$ increases, the second resonance frequency $f_{2}$ moves upward. From the figure, one can also see that the resonant frequency is of $2.6 \mathrm{GHz}$ and the impedance bandwidth is 2.148 $2.697 \mathrm{GHz}$, thus covering the LTE2300/LTE2500 frequency band, when the length $L 2$ is of $11 \mathrm{~mm}$. Therefore, the length of the parameter $L 2$ is set to $11 \mathrm{~mm}$.

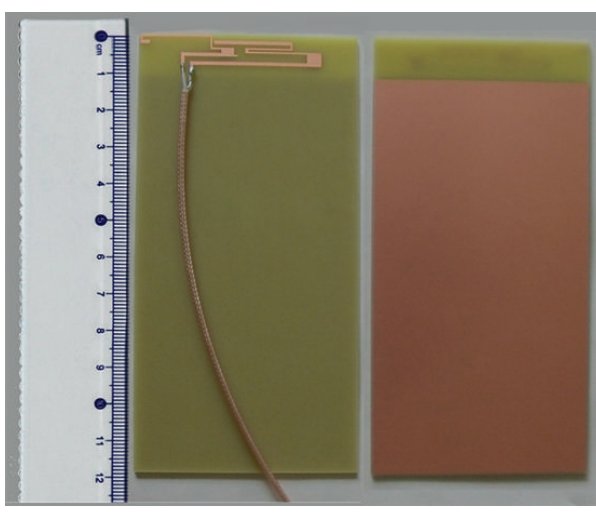

Figure 2: Photograph of the fabricated antenna with short feeding cable.

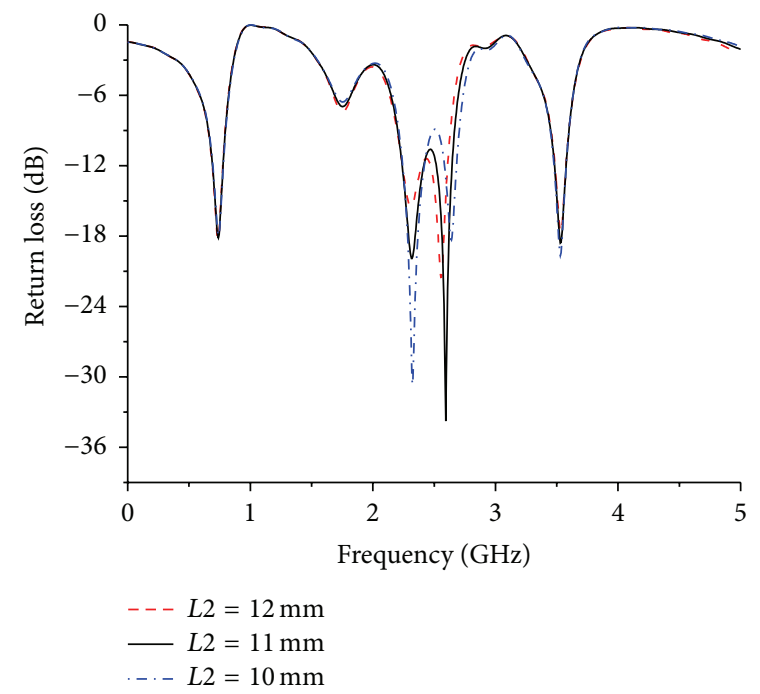

Figure 3: Simulated return loss characteristics for the proposed antenna for various values of $L 2$.

Figure 4 illustrates the frequency behavior of the antenna reflection coefficient when the length of the parameter $L 7$ varies from $15 \mathrm{~mm}$ to $17 \mathrm{~mm}$ when the other parameters are kept constant. From this figure it appears that the third resonance frequency $f_{3}$ moves downward as the length of the parameter $L 7$ is increased. The length of $L 7$ mainly controls the third resonance frequency $f_{3}$ for the $3.5 \mathrm{GHz}$ WiMAX band. As is shown in Figure 4, when $L 7$ is equal to $16 \mathrm{~mm}$, the resonant frequency is of $3.53 \mathrm{GHz}$ while the antenna bandwidth is in the frequency range $3.392 \sim 3.632 \mathrm{GHz}$. Therefore, the length of the parameter $L 7$ is set to $16 \mathrm{~mm}$ so as to assure a resonance frequency at $f_{3}$.

A different behavior of the reflection coefficient with respect to the variation of the geometrical parameter $L 8$ is observed in Figure 5. In fact, when this parameter increases from $18 \mathrm{~mm}$ to $22 \mathrm{~mm}$, while maintaining the other structure parameters to the values of the optimized design, both the first resonance frequency $f_{1}$ and the third resonance frequency $f_{3}$ move downward. In particular, when $L 8$ is of $20 \mathrm{~mm}$, the first resonance frequency $f_{1}$ and impedance 


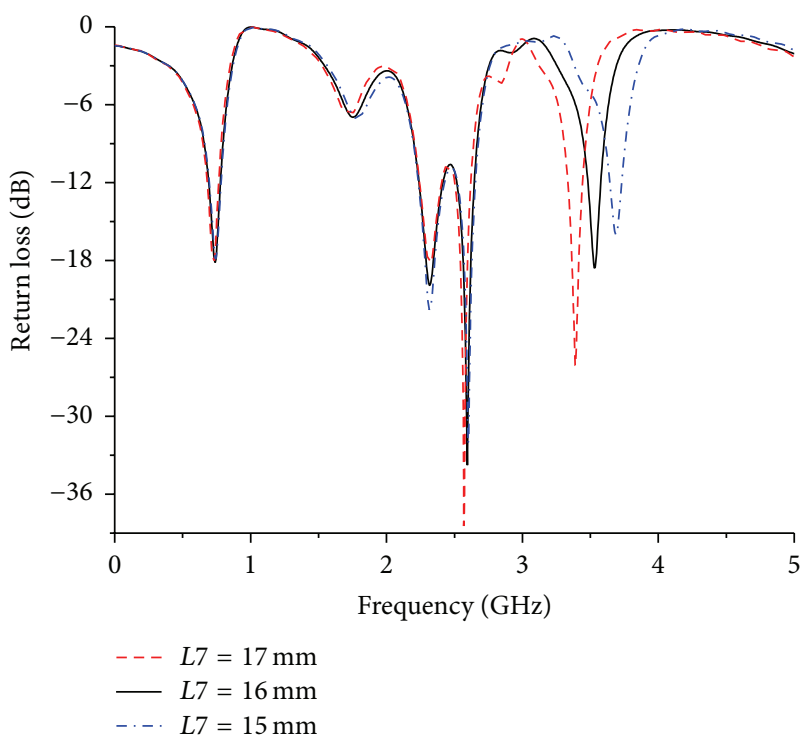

FIGURE 4: Simulated return loss characteristics for the proposed antenna for various values of $L 7$.

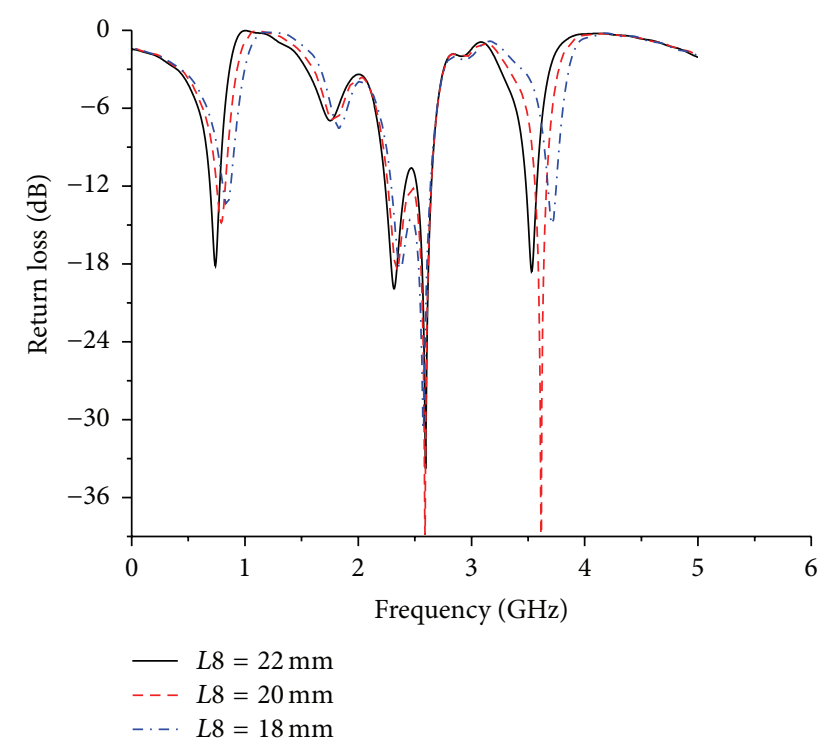

FIGURE 5: Simulated return loss characteristics for the proposed antenna for various values of $L 8$.

bandwidth are $0.74 \mathrm{GHz}$ and $0.590 \sim 0.823 \mathrm{GHz}$ covering LTE700, respectively. Thus, the parameter $L 8$ is set to $20 \mathrm{~mm}$.

Finally, in Figure 6 the simulated return loss of the proposed antenna for the different values of the widths $W 5$ is shown. As in the other cases the other antenna geometrical parameters are kept constant. From Figure 6 it can be seen that both the first resonance frequency $f_{1}$ and the third resonance frequency $f_{3}$ move upward as the width $W 5$ increases. In particular, when the width of $W 5$ equals $1.5 \mathrm{~mm}$, the first resonance frequency is $0.74 \mathrm{GHz}$ and the impedance bandwidth defined by $6 \mathrm{~dB}$ return loss is 0.590 $0.823 \mathrm{GHz}$, thus covering the LTE700 frequency band. At the same time, the third resonance frequency is $3.5 \mathrm{GHz}$ and

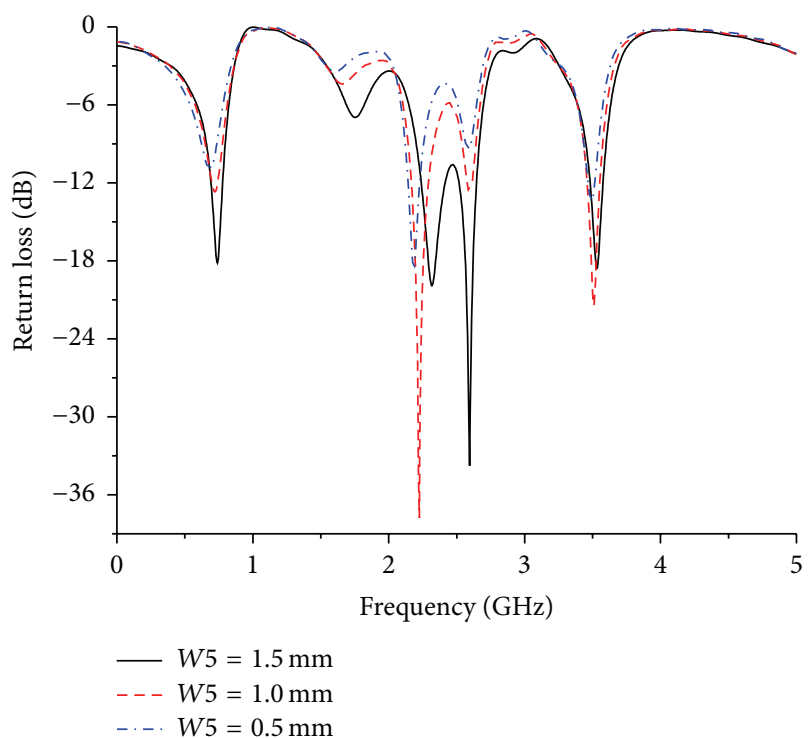

FIGURE 6: Simulated return loss characteristics for the proposed antenna for various values of $W 5$.

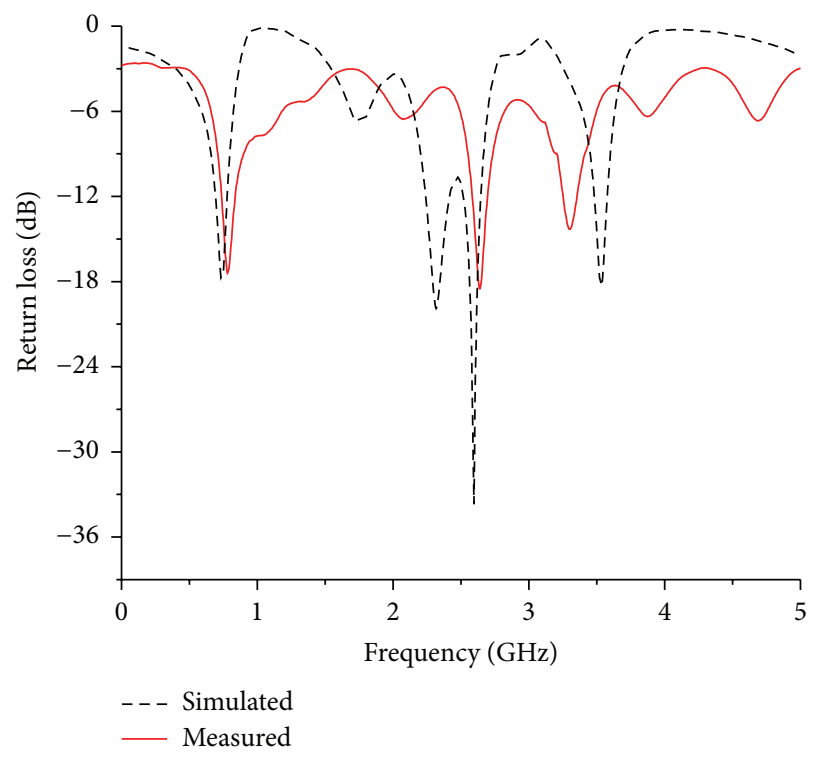

FIGURE 7: Simulated and measured return loss versus frequencies of the proposed antenna.

the impedance bandwidth is $210 \mathrm{MHz}(3.39 \sim 3.60 \mathrm{GHz})$ at the $3.5 \mathrm{GHz}$ WiMAX band. Therefore, the parameter $W 5$ is chosen to be $W 5=1.5 \mathrm{~mm}$.

\section{Results and Discussions}

An antenna prototype (see Figure 2) designed using the geometric parameters obtained by means of the parametric analysis presented above has been realized and measured. The proposed antenna has been measured using an Agilent PNA 8362B Network Analyzer in a frequency range from 45 to $5000 \mathrm{MHz}$. Figure 7 compares the frequency behavior of the simulated and measured return loss (reflection 


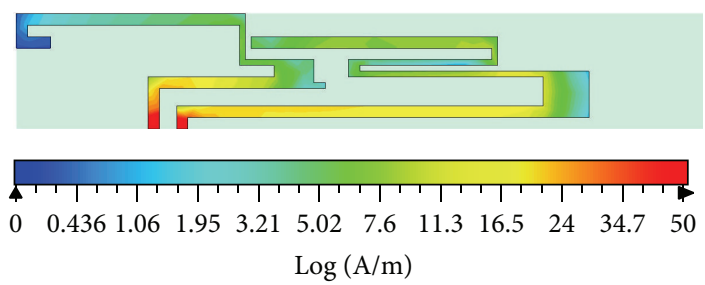

(a) $f=0.75 \mathrm{GHz}$

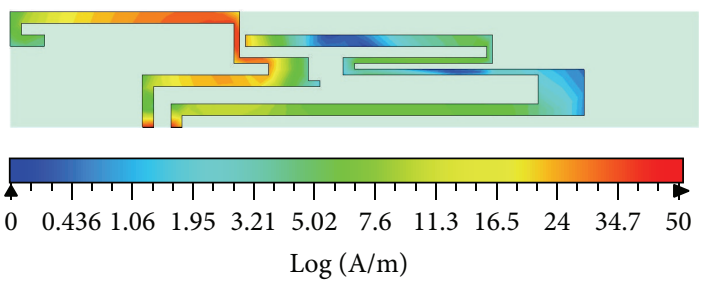

(b) $f=2.6 \mathrm{GHz}$

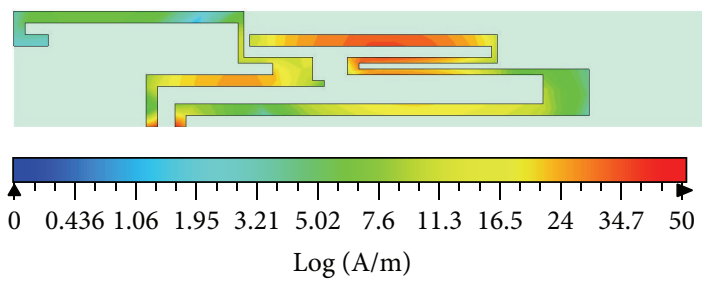

(c) $f=3.5 \mathrm{GHz}$

FIGURE 8: Surface current distributions on the radiating patch at (a) $0.75 \mathrm{GHz}$; (b) $2.6 \mathrm{GHz}$; and (c) $3.5 \mathrm{GHz}$.

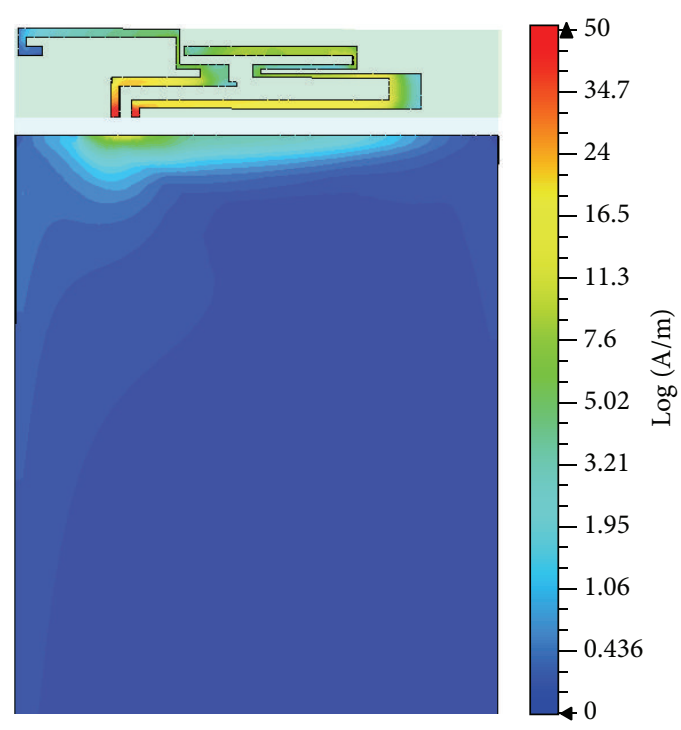

(a) $f=0.75 \mathrm{GHz}$

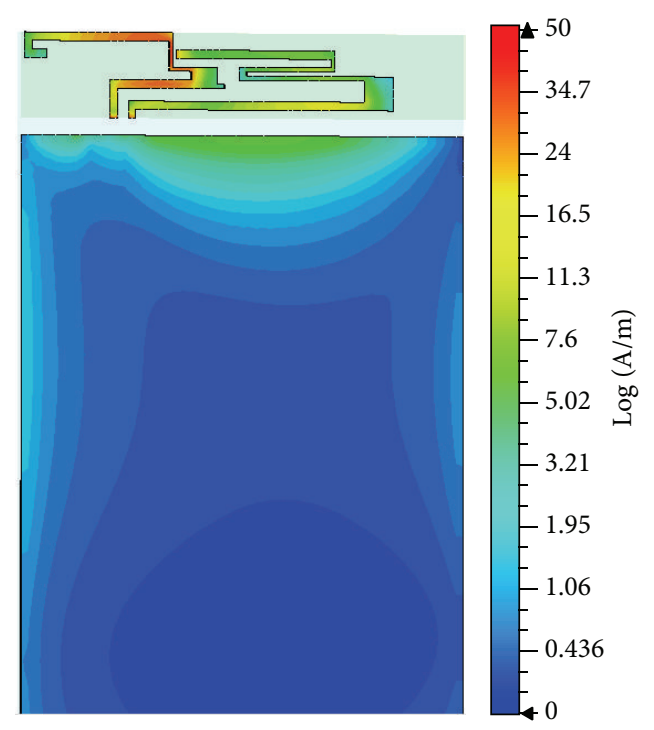

(b) $f=2.6 \mathrm{GHz}$

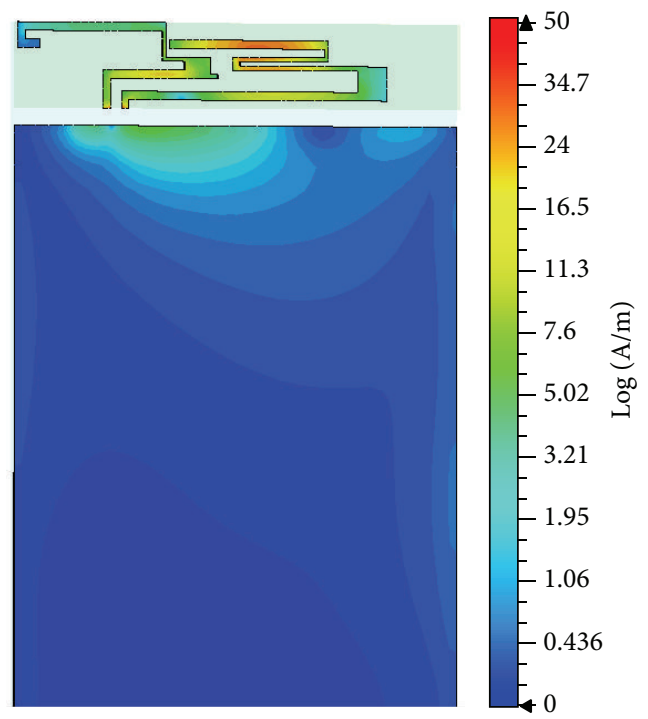

(c) $f=3.5 \mathrm{GHz}$

FIGURE 9: Surface current distributions on the proposed antenna at (a) $0.75 \mathrm{GHz}$; (b) $2.6 \mathrm{GHz}$; and (c) $3.5 \mathrm{GHz}$. 


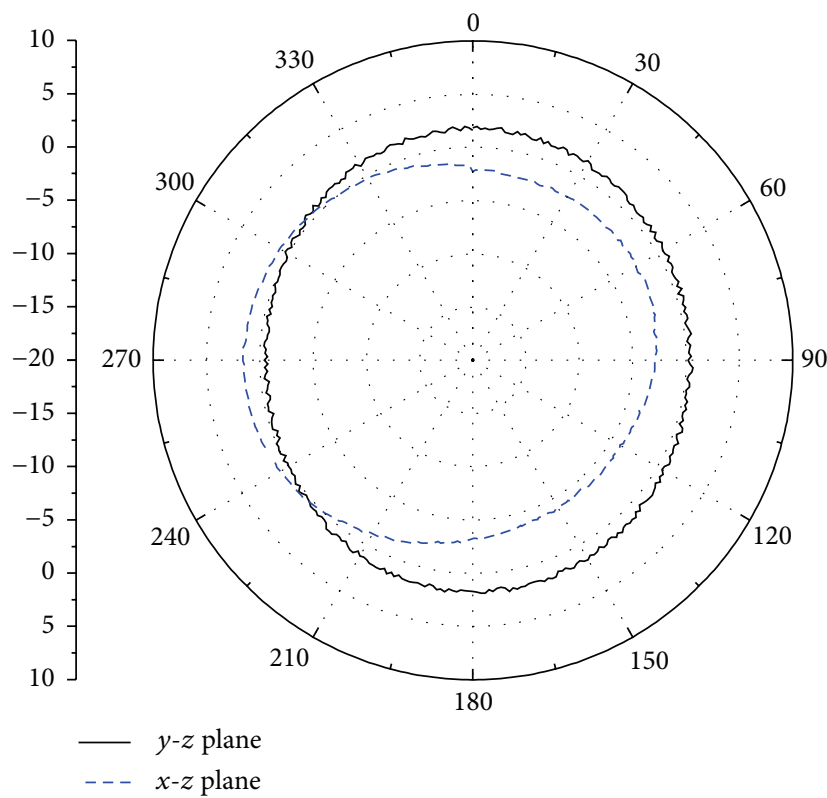

(a)

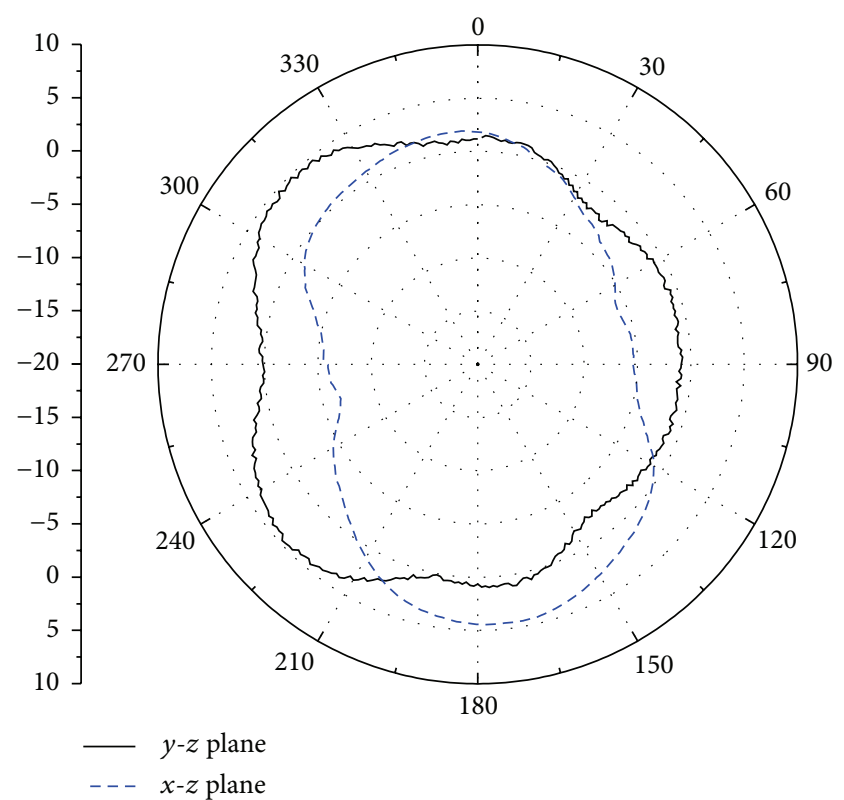

(b)

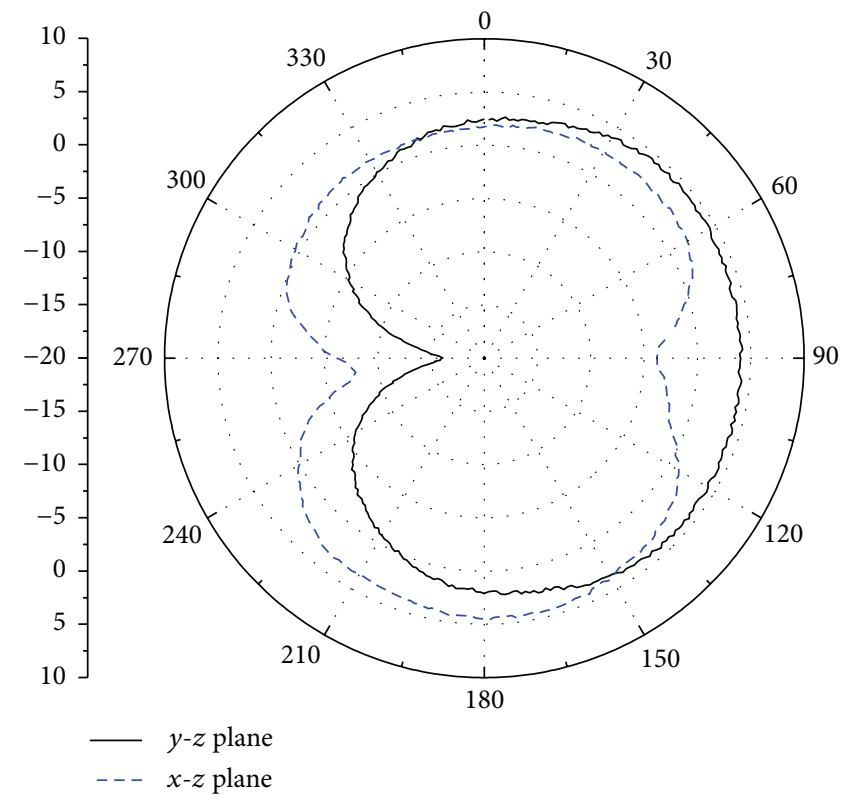

(c)

FIGURE 10: Measured radiation patterns of the proposed antenna for the LTE operation frequencies at (a) $0.75 \mathrm{GHz}$; (b) $2.6 \mathrm{GHz}$; and (c) $3.5 \mathrm{GHz}$.

coefficients) of the proposed antenna. All frequency bands are covered within the $6 \mathrm{~dB}$ of return loss, which is a widely used standard in the mobile phone antennas. The discrepancy observed between the computed and measured values of the reflection coefficient is due to the substrate and realization tolerances, as well as to the effect of the SMA connector and of the soldering points. When the antenna is carefully realized the measured impedance bandwidth is of $230 \mathrm{MHz}(0.59 \mathrm{GHz} \sim 0.82 \mathrm{GHz}, 32.6 \%)$ for the LTE 700 (698-787 MHz), of $550 \mathrm{MHz}(2.15 \mathrm{GHz} 2.70 \mathrm{GHz}, 22.68 \%)$ for the LTE2300 (2305-2400 MHz) and the LTE2500 (2500$2690 \mathrm{MHz})$, and of $230 \mathrm{MHz}(3.40 \mathrm{GHz} 3.63 \mathrm{GHz}, 6.54 \%)$ for the $3.5 \mathrm{GHz}$ WiMAX.

The numerical simulations were performed using the fullwave commercial software HFSS. This software was used to evaluate and verify the three resonant frequencies 0.75 , 2.6 , and $3.5 \mathrm{GHz}$, which mainly depend on the lengths of the different current paths along the two horizontal-U rings. Figures $8(a)-8(c)$ show the surface current density excited along the two horizontal- $U$ rings antennas at the three 
resonant frequencies $0.75,2.6$, and $3.5 \mathrm{GHz}$, respectively. In Figure 8(a), the lowest band surface current density distribution along the two input antenna ports at the resonant frequency of $0.75 \mathrm{GHz}$ is shown. A larger surface current density flows along the first horizontal-U ring when the resonant frequency is $2.6 \mathrm{GHz}$ as it is observed in Figure 8(b). However, larger surface current densities flow along the second horizontal- $U$ ring when the resonant frequency is $3.5 \mathrm{GHz}$ as is shown in Figure 8(c). Figures 9(a)-9(c) show the surface current density excited along the radiating patch and on the ground plane at the three resonant frequencies $0.75,2.6$, and $3.5 \mathrm{GHz}$, respectively. The emission phenomena take place along the $\mathrm{U}$ rings, at the patch corners, and at the substrate truncations where the conversion of surface waves into volume waves occurs [17]. In conclusion, the maximum amplitude of the surface current distribution excited on the antenna at the three resonant frequencies is located in different parts of the radiating structure.

Figure 10 shows the measured far-field radiation patterns in the $E$ plane ( $x-z$ plane) and $H$ plane ( $y-z$ plane). Figures 10 (a) -10 (c) show the radiation patterns at $0.75 \mathrm{GHz}, 2.6 \mathrm{GHz}$, and $3.5 \mathrm{GHz}$, which are the resonance centre frequencies, respectively. That is to say, the proposed printed antenna covers three LTE bands and one WiMAX band. As evidenced by the radiation patterns it appears that the proposed antenna displays nearly omnidirectional radiation characteristics in the $H$ plane, and monopole-like radiation pattern characteristics in the $E$ plane at the considered frequencies. Moreover, since the planar radiating structure is realized on a single side printed circuit board is easy to manufacture.

\section{Conclusions}

A planar antenna for $4 \mathrm{G}$ mobile communication systems has been presented, realized, and tested experimentally. The obtained impedance bandwidth across the operating bands can reach about $356 / 413 / 237 \mathrm{MHz}$ for the LTE bands and $210 \mathrm{MHz}$ for the WiMAX band while the peak gains are about 2.1/4.7/4.3 dBi and $4.3 \mathrm{dBi}$, respectively. Good radiation characteristics across the operative bands have been also confirmed. The proposed antenna has a planar structure so it is easy to fabricate at low cost by printing it directly on the flexible printed circuit board of the mobile phone. Therefore, the proposed antenna meets the challenging requirements of the modern mobile phone communications.

\section{Competing Interests}

The authors declare that they have no competing interests.

\section{Acknowledgments}

The authors gratefully acknowledge the financial support from the Zhejiang Province Natural Science Fund under Grant no. LY15F050006 and National Natural Science Foundation of China under Grants nos. 61379024 and 61131005.

\section{References}

[1] C.-H. Wu and K.-L. Wong, "Ultrawideband PIFA with a capacitive feed for penta-band folder-type mobile phone antenna," IEEE Transactions on Antennas and Propagation, vol. 57, no. 8, pp. 2461-2464, 2009.

[2] H. S. Singh, M. Agarwal, G. K. Pandey, and M. K. Meshram, "A quad-band compact diversity antenna for GPS L1/Wi-Fi/ LTE2500/WiMAX/HIPERLAN1 applications," IEEE Antennas and Wireless Propagation Letters, vol. 13, pp. 249-252, 2014.

[3] C. Y. D. Sim, K. R. Chen, and W. B. He, "A uniplanar printed antenna with an inverted L-shaped coupling feed for LTE/GSM/ DCS/PCS/UMTS operations," International Journal of RF and Microwave Computer-Aided Engineering, vol. 22, no. 5, pp. 610618, 2012.

[4] M. E. de Cos, M. Mantash, A.-C. Tarot, and F. Las-Heras, "Dualband coplanar waveguide-fed smiling monopole antenna for $\mathrm{WiFi}$ and 4G long-term evolution applications," IET Microwaves, Antennas and Propagation, vol. 7, no. 9, pp. 777-782, 2013.

[5] J. Ilvonen, R. Valkonen, J. Holopainen, and V. Viikari, "Multiband frequency reconfigurable $4 \mathrm{G}$ handset antenna with MIMO capability," Progress in Electromagnetics Research, vol. 148, pp. 233-243, 2014.

[6] P. V. Naidu and A. Malhotra, "A small ACS-fed tri-band antenna employing $\mathrm{C}$ and L shaped radiating branches for LTE/WLAN/ WiMAX/ITU wireless communication applications," Analog Integrated Circuits and Signal Processing, vol. 85, no. 3, pp. 489496, 2015.

[7] J.-H. Lu and F.-C. Tsai, "Planar small-size LTE/WWAN tablet computer antenna with eight-band operation," Journal of Electromagnetic Waves and Applications, vol. 29, no. 8, pp. 10321046, 2015.

[8] X. Zhao, K. Kwon, and J. Choi, "MIMO antenna using resonance of ground planes for $4 \mathrm{G}$ mobile application," Journal of Electromagnetic Engineering and Science, vol. 13, no. 1, pp. 51-53, 2013.

[9] S. Verma and P. Kumar, "Compact triple-band antenna for WiMAX and WLAN applications," Electronics Letters, vol. 50, no. 7, pp. 484-486, 2014.

[10] Y. Li and W. Yu, "A miniaturized triple band monopole antenna for WLAN and WiMAX applications," International Journal of Antennas and Propagation, vol. 2015, Article ID 146780, 5 pages, 2015.

[11] A. M. Asghar, M. Malick, M. Karlsson, and A. Hussain, "A multiwideband planar monopole antenna for $4 \mathrm{G}$ devices," Microwave and Optical Technology Letters, vol. 55, no. 3, pp. 589-593, 2013.

[12] J. H. Lee and Y. Sung, "A simple penta-band reconfigurable antenna for mobile device applications," Microwave and Optical Technology Letters, vol. 56, no. 3, pp. 769-774, 2014.

[13] C.-H. Chang and K.-L. Wong, "Printed $\lambda / 8$-PIFA for pentaband WWAN operation in the mobile phone," IEEE Transactions on Antennas and Propagation, vol. 57, no. 5, pp. 1373-1381, 2009.

[14] D. Kang and Y. Sung, "Compact hexaband PIFA antenna for mobile handset applications," IEEE Antennas and Wireless Propagation Letters, vol. 9, pp. 1127-1130, 2010.

[15] A. Cabedo, J. Anguera, C. Picher, M. Ribó, and C. Puente, "Multiband handset antenna combining a PIFA, slots, and ground plane modes," IEEE Transactions on Antennas and Propagation, vol. 57, no. 9, pp. 2526-2533, 2009. 
[16] Y. K. Park and Y. Sung, "A reconfigurable antenna for quad-band mobile handset applications," IEEE Transactions on Antennas and Propagation, vol. 60, no. 6, pp. 3003-3006, 2012.

[17] D. Caratelli, R. Cicchetti, G. Bit-Babik, and A. Faraone, "Circuit model and near-field behavior of a novel patch antenna for WWLAN applications," Microwave and Optical Technology Letters, vol. 49, no. 1, pp. 97-100, 2007. 


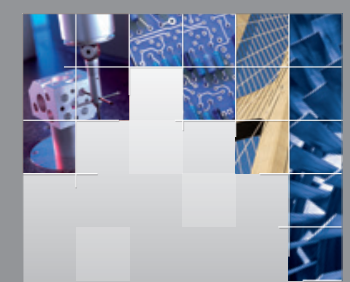

\section{Enfincering}
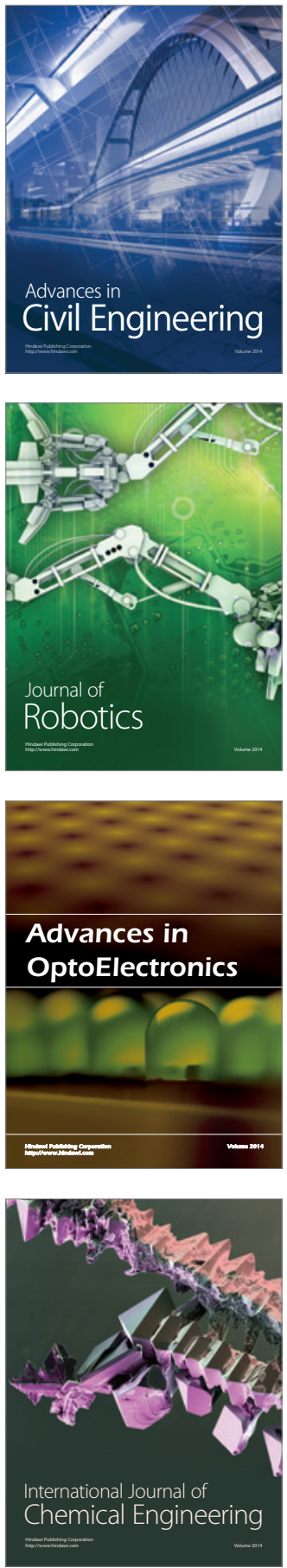

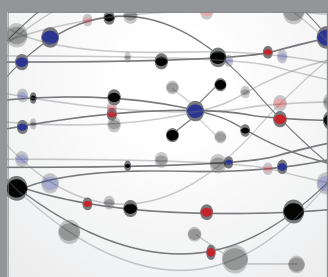

The Scientific World Journal

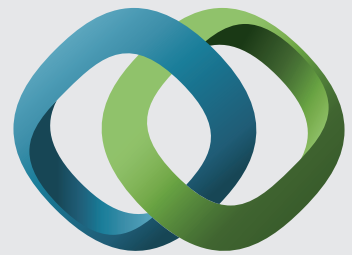

\section{Hindawi}

Submit your manuscripts at

http://www.hindawi.com
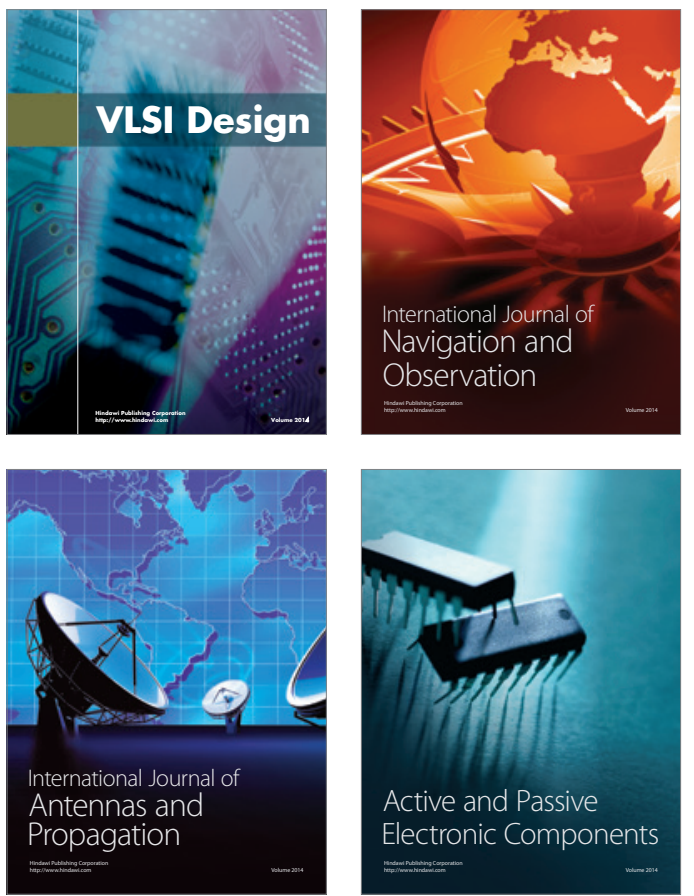
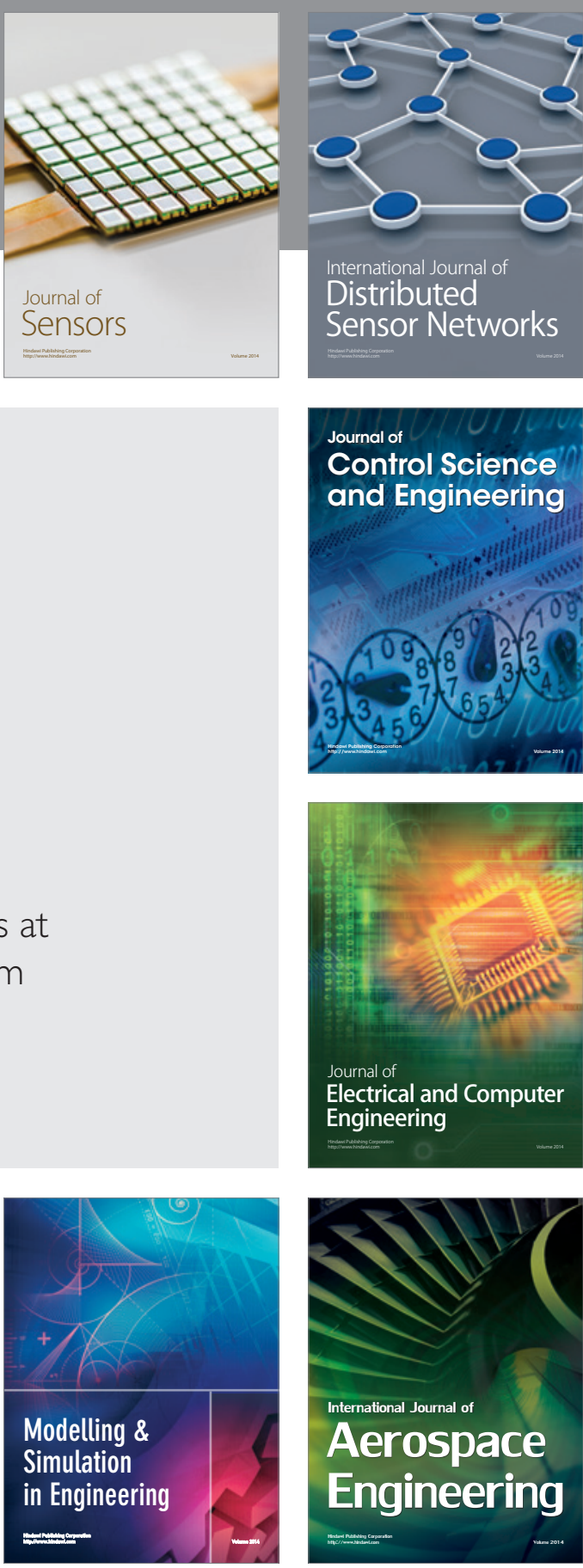

International Journal of

Distributed

Sensor Networks

Journal of

Control Science

and Engineering
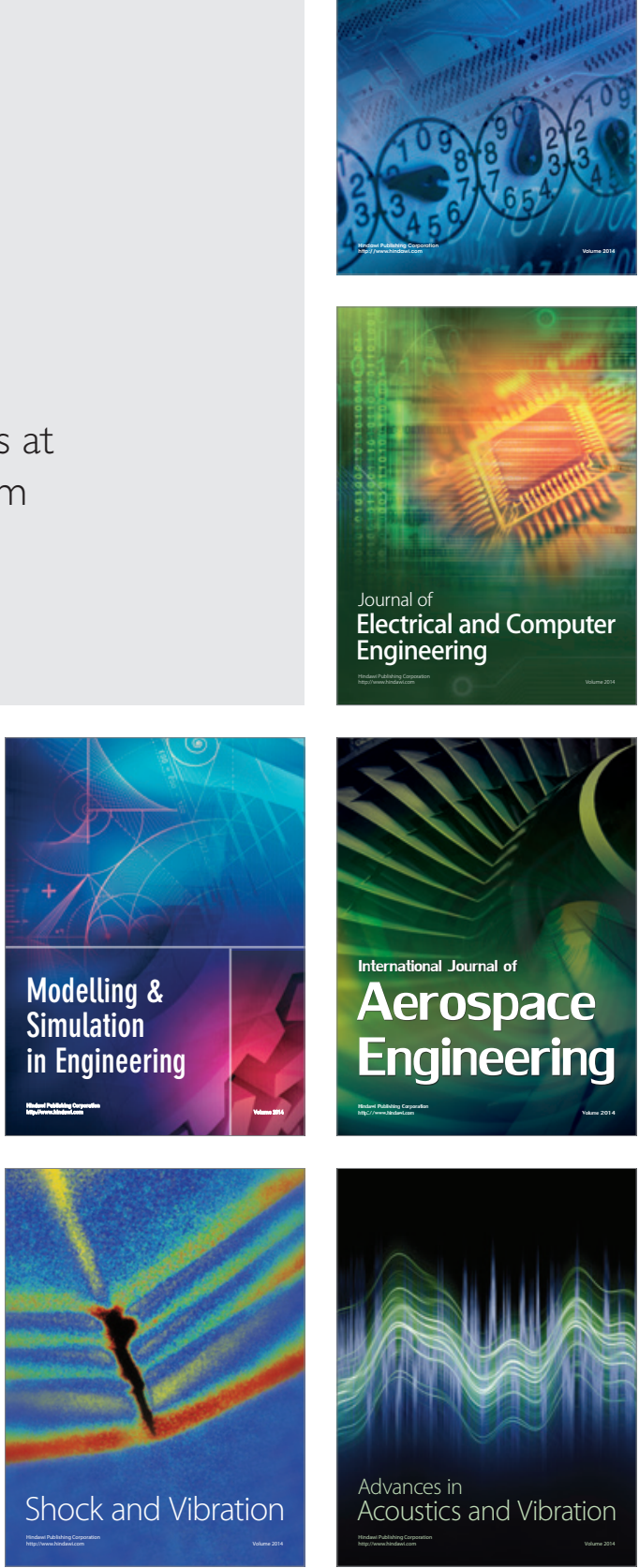